\title{
Manifestaciones mucocutáneas atípicas por fiebre por el virus del chikungunya en neonatos y lactantes de Cúcuta, Los Patios y Villa del Rosario, Norte de Santander, Colombia, 2014
}

\author{
Claudia Marcela Muñoz ${ }^{1}$, José Orlando Castillo², Daniela Salas ${ }^{3}$, Milena Alexandra Valderrama ${ }^{4}$,
} Claudia Teresa Rangel ${ }^{5}$, Heiddy Patricia Vargas ${ }^{4}$, Diana Carolina Silva ${ }^{5}$

1 Grupo de Epidemiología Aplicada, Dirección de Vigilancia y Análisis del Riesgo en Salud Pública, Instituto Nacional de Salud, Bogotá, D.C., Colombia

2 Grupo de Enfermedades Transmisibles, Dirección de Vigilancia y Análisis del Riesgo en Salud Pública, Instituto Nacional de Salud, Bogotá, D.C., Colombia

3 Grupo de Enfermedades Transmitidas por Vectores, Dirección de Vigilancia y Análisis del Riesgo en Salud Pública, Instituto Nacional de Salud, Bogotá, D.C., Colombia

4 Grupo de Vigilancia en Salud Pública, Instituto Departamental de Salud de Norte de Santander, Cúcuta, Colombia

5 Vigilancia en Salud Pública, Secretaría de Salud Municipal de Cúcuta, Cúcuta, Colombia

Introducción. Se han observado manifestaciones clínicas atípicas en recién nacidos y lactantes con fiebre por el virus del chikungunya.

Objetivo. Describir los casos de fiebre causada por el virus del chikungunya en recién nacidos y lactantes con lesiones mucocutáneas atípicas.

Materiales y métodos. Se revisaron las historias clínicas y los resultados de laboratorio y de patología en tres hospitales regionales de los casos de recién nacidos y lactantes diagnosticados con el virus del chikungunya que presentaban lesiones mucocutáneas atípicas; se hizo una búsqueda activa comunitaria en los barrios de residencia de los pacientes.

Resultados. De 18 casos sospechosos de chikungunya en recién nacidos y lactantes, 11 pacientes con diagnóstico confirmado presentaron manifestaciones mucocutáneas atípicas. Seis de los 11 casos confirmados eran niños menores de cinco meses de edad. Los síntomas más frecuentes fueron: fiebre, eritema, irritabilidad y diarrea. Tres de los pacientes estaban infectados con dengue y chikungunya. Las úlceras se presentaron en cuero cabelludo, abdomen, región genital y perianal. En la búsqueda activa comunitaria se encontraron altas tasas de ataque de la enfermedad.

Conclusiones. Se presenta un informe de las manifestaciones mucocutáneas en recién nacidos y lactantes diagnosticados con fiebre por el virus del chikungunya en Colombia. El rápido desarrollo de las úlceras se debe, probablemente, a la reacción inmunitaria al virus. Es necesario priorizar la atención de las mujeres embarazadas que presenten síntomas una semana antes del parto y hacerle seguimiento a los recién nacidos, para hacer el diagnóstico temprano del chikungunya y evitar complicaciones.

Palabras clave: virus chikungunya/epidemiología, brotes de enfermedades, recién nacido, úlcera cutánea, manifestaciones cutáneas.

doi: http://dx.doi.org/10.7705/biomedica.v36i3.2760

Atypical mucocutaneous manifestations in neonates and infants with chikungunya fever in the municipalities of Cúcuta, Los Patios and Villa del Rosario, Norte de Santander, Colombia, 2014

Introduction: Atypical clinical manifestations have been observed in newborns and infants suffering from fever caused by the chikungunya virus.

Objective: To describe the cases of fever caused by the chikungunya virus in newborns and infants with atypical mucocutaneous lesions.

Materials and methods: We reviewed the clinical records, as well as lab tests and histopathological results, of newborns and infants diagnosed with Chikungunya virus and atypical mucocutaneous lesions in three regional hospitals.

Results: Out of 18 suspected cases of chikungunya virus in newborns and infants, 11 were positive and presented atypical mucocutaneous manifestations. Six of the eleven confirmed cases corresponded to children under five months of age. The most common symptoms were fever, skin rash, irritability, and

\section{Contribución de los autores:}

Todos los autores participaron en el trabajo de campo, la recolección de la información y la escritura del manuscrito. 
diarrhea. Three of the patients were infected with both dengue and chikungunya viruses. The ulcers occurred in the scalp, abdomen, genital and perianal region.

Conclusions: We report mucocutaneous manifestations in newborns and infants diagnosed with fever caused by the chikungunya virus in Colombia. The rapid development of ulcers is most likely due to the immune response to the virus. Special attention should be given to pregnant women presenting symptoms of chikungunya virus infection prior to delivery, and their offspring should be followed-up in order to monitor possible complications.

Key words: Chikungunya virus/epidemiology; disease outbreaks; infant, newborn; skin ulcer; skin manifestations.

doi: http://dx.doi.org/10.7705/biomedica.v36i3.2760

Los primeros brotes de chikungunya se presentaron en los años 50 del siglo pasado en Tanzania, Uganda y Zimbabwe (África) y, posteriormente, hubo casos en Bangkok (Asia), en 1958. En el 2005, se presentaron grandes epidemias en África y en las islas del océano Índico, las cuales afectaron a más de un millón de personas (1). Los primeros casos autóctonos en una zona no tropical se registraron en Italia en el 2007 (2), y en algunos estudios en este país y en la isla Reunión se reportó un alto porcentaje de casos asintomáticos con serología positiva $(3,4)$.

A partir de diciembre del 2013, se presentó una gran epidemia de fiebre por el virus del chikungunya en la región de las Américas, la cual se ha convertido en un grave problema de salud pública y en un reto para los sistemas de vigilancia y los servicios de salud en varios países.

El virus del chikungunya es un arbovirus del género Alphavirus, familia Togaviridae, transmitido por mosquitos Aedes aegypti y A. albopictus. Es originario de África donde se presenta la transmisión a primates por mosquitos Aedes selváticos del subgénero $A$. stegomyia y $A$. diceromyia en un ciclo que dura tres años (5).

Su periodo de incubación es de uno a 12 días, se caracteriza por una alta carga viral, y produce linfopenia pronunciada y trombocitopenia moderada (6). Las manifestaciones de la fiebre del chikungunya se clasifican en típicas y atípicas. Las típicas se caracterizan por fiebre de inicio súbito, dolor en las articulaciones, mialgias y erupción cutánea; en

\footnotetext{
Correspondencia:

Claudia Marcela Muñoz, Grupo de Epidemiología Aplicada, Dirección de Vigilancia y Análisis del Riesgo en Salud Pública, Instituto Nacional de Salud, Avenida Calle 26 № 51-20, Bogotá, D.C., Colombia

Teléfono: (571) 220 7700, extensiones 1382 y 1486

cmunoz@ins.gov.co
}

Recibido: 20/03/15; aceptado: 20/03/16 algunos pacientes se observan adenomegalias cervicales, náuseas, vómitos, edema facial, inflamación de la vulva o el escroto y manifestaciones como vesículas y pigmentaciones en la piel, principalmente en extremidades, tronco y cara (7-9). Las manifestaciones atípicas pueden ser efecto directo del virus y pueden afectar los sistemas neurológico, ocular, cardiovascular y renal. Los efectos en la piel incluyen hiperpigmentación, fotosensibilidad, dermatitis exfoliativa, eritema, úlceras intertriginosas y dermatosis ampollosa $(6,8)$.

En India y en la isla Reunión, se han documentado manifestaciones atípicas de la infección con el virus, como meningoencefalitis, hepatitis aguda, aftas, úlceras cutáneas y erupciones ampollosas (1012). En India, se clasificaron las manifestaciones mucocutáneas de la fiebre del chikungunya en seis categorías: erupción cutánea, aftas ulcerosas, cambios de pigmentación en la cara, descamación en la piel, exacerbación de las dermatosis existentes $y$, por último, una miscelánea de síntomas que incluye urticaria, úlceras cutáneas necróticas no intertriginosas, inflamación escrotal, edema y erupciones ampollosas (11), los cuales pueden deberse a la mutación del virus, a la reacción inmunitaria o la toxicidad de algunos medicamentos, y afectan con mayor frecuencia a los niños y los lactantes. Según un estudio, en la isla Reunión se presentaron casos de infección neonatal, de meningoencefalitis y de trastornos graves de la piel (12). En otro estudio se reportaron lesiones cutáneas ampollosas en menores de tres meses de edad (13).

Los primeros casos de transmisión autóctona de la fiebre del chikungunya en América ocurrieron en la isla San Martín en diciembre de 2013 (14) y afectaron a más de 300 personas. Hasta la semana 51 de 2014, se reportaron en este continente más de 1'046.569 casos sospechosos y 22.284 casos confirmados (15), en tanto que 45 países ya habían notificado casos de transmisión autóctona 
en diciembre de 2014. Esta rápida diseminación del virus presagia su llegada a otras áreas de la región en corto tiempo, ya que la población no es inmune y la presencia del vector es un factor clave para la continua transmisión del virus.

Hasta la semana epidemiológica 51 de 2014, se habían notificado en Colombia 87.477 casos: 85.439 de ellos confirmados por clínica, 760 sospechosos y 1.274 confirmados por laboratorio (16). Los lugares que presentaron el mayor número de casos fueron Norte de Santander, Sucre, Bolívar y Cartagena, que corresponden a $72 \%$ de los casos notificados en el país. Según el Instituto Nacional de Salud, las condiciones que favorecen la rápida difusión del virus son la presencia del vector $A$. aegypti en el domicilio y la vulnerabilidad de las personas (17).

Por otra parte, el Centro Nacional de Enlace informó al Instituto Nacional de Salud la muerte de dos recién nacidos, probablemente asociada a la fiebre del chikungunya, en los municipios de Los Patios y Cúcuta. La Dirección de Vigilancia y Análisis del Riesgo en Salud Pública del Instituto Nacional de Salud decidió apoyar la investigación de campo y documentar los casos presentados. Posteriormente, en una reunión del Instituto Departamental de Salud de Norte de Santander con la Secretaría de Salud Municipal de Cúcuta, se verificó la información de los casos, se aclaró que solo se presentó una muerte asociada al virus del chikungunya y se detectaron 17 casos más en recién nacidos y lactantes.

El objetivo de este estudio fue describir los casos de fiebre causada por el virus del chikungunya en recién nacidos y lactantes con lesiones mucocutáneas atípicas, con el fin de orientar las acciones de salud pública pertinentes en la población en riesgo.

\section{Materiales y métodos}

El estudio se llevó a cabo en tres hospitales regionales de tercer nivel de complejidad, ubicados en Cúcuta. Se revisaron los casos de recién nacidos y lactantes hasta diciembre de 2014 con diagnóstico del virus del chikungunya y lesiones mucocutáneas atípicas, los cuales procedían de los municipios de Cúcuta, Los Patios y Villa del Rosario.

Se establecieron las siguientes definiciones de caso.

Caso sospechoso: recién nacido o lactante procedente de los municipios de Cúcuta, Los Patios y Villa del Rosario que presentara fiebre, erupción, irritación y lesiones mucocutáneas.
Caso confirmado por laboratorio: caso sospechoso con resultado positivo en las pruebas de laboratorio específicas para chikungunya (PCR$\mathrm{RT}$ e $\lg \mathrm{M})$.

Caso confirmado por clínica: caso sospechoso sin pruebas de laboratorio, que reuniera los criterios clínicos y epidemiológicos en pacientes procedentes de los municipios en donde hubiera un brote (18).

El diagnóstico de la infección por chikungunya se confirmó mediante la detección del genoma viral en suero, utilizando la reacción en cadena de la polimerasa con transcripción inversa (PCR-RT) durante la fase aguda de la enfermedad, o mediante la detección de IgM anti-CHIKV. Estas pruebas se llevaron a cabo en el Grupo de Arbovirus del Laboratorio de Virología del Instituto Nacional de Salud. Para la detección de los anticuerpos IgM en el diagnóstico de chikungunya y dengue, se utilizó un sistema inmunoenzimático que permite la detección y la titulación de inmunoglobulinas totales para ambos virus.

Se analizaron las historias clínicas y las fichas epidemiológicas de cada paciente, para determinar las variables sociodemográficas, la sintomatología y los antecedentes de las madres, los resultados de laboratorio, el tratamiento farmacológico y el estado del paciente en el momento del egreso hospitalario. Se solicitaron las pruebas de laboratorio para chikungunya y dengue, y se revisaron los resultados de las biopsias de las lesiones, en las cuales se habían utilizado tinciones especiales, como el ácido peryódico de Schiff y la tinción de Ziehl-Neelsen.

La información se analizó utilizando números absolutos y porcentajes, y se calcularon las frecuencias simples y las medidas de tendencia central. Los datos se procesaron en Excel 2010.

\section{Consideraciones éticas}

El estudio se clasificó como una investigación sin riesgo con base en la Resolución 8430 de 1993 del Ministerio de Salud. La información se extrajo de las historias clínicas, y de los resultados de laboratorio y de patología. Se respetaron los principios de responsabilidad, proporcionalidad y confidencialidad de la información.

Los resultados de este estudio aportarán a la caracterización de los casos de chikungunya en el país y sus manifestaciones atípicas, como respaldo a las decisiones referentes a su vigilancia, diagnóstico y manejo. 


\section{Resultados}

\section{Descripción de la zona de estudio}

Los municipios de Cúcuta, Villa del Rosario y Los Patios están ubicados en el departamento de Norte de Santander, zona nororiental del país, en límites con Venezuela, y hacen parte del área metropolitana de Cúcuta (figura 1). Más del $90 \%$ de su población se encuentra en el área urbana, y las actividades económicas se relacionan con el comercio y el turismo.

La cobertura del servicio de acueducto en Villa del Rosario es de 74,6 \% y, en Los Patios, de $75 \%$; en ambos municipios la calidad del agua es deficiente y su distribución es intermitente, pues se distribuye cada ocho a 15 días en algunos sectores (19-20). En Cúcuta, el servicio de acueducto en algunos sectores también es intermitente y el suministro se hace en tanques o cisternas. Estos problemas de abastecimiento de agua en los tres municipios obligan a la población a almacenarla en tanques, canecas y baldes, situación que propicia la reproducción del vector del chikungunya y del dengue en la región.

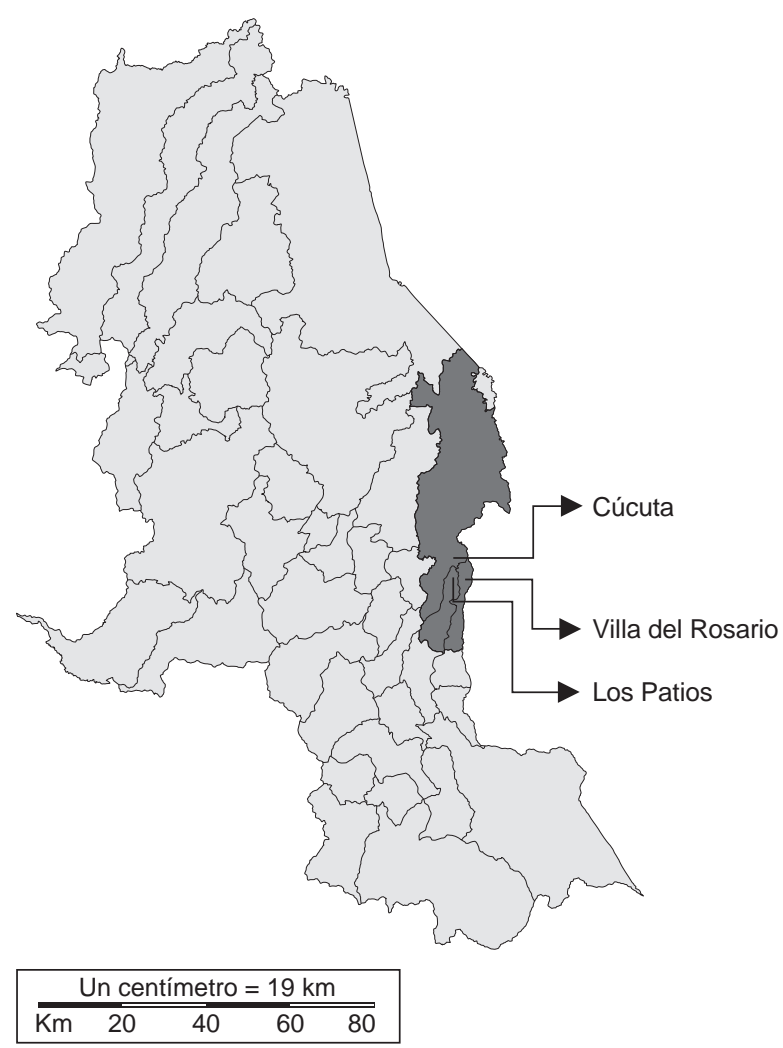

Figura 1. Ubicación de los municipios de Cúcuta, Villa del Rosario y Los Patios, Norte de Santander, Colombia
En la semana epidemiológica 50 de 2014, se reportaron al sistema de vigilancia 7.762 casos de chikungunya en los municipios de Cúcuta, Villa del Rosario y Los Patios (figura 2).

\section{Descripción de los casos}

Se encontraron 18 neonatos y lactantes que consultaron por síntomas sugestivos de infección por el virus del chinkungunya; 12 de ellos presentaban lesiones importantes de tipo vesicular en la piel, las cuales evolucionaron a úlceras. Se confirmaron 11 casos de fiebre del chikungunya con manifestaciones mucocutáneas atípicas (ocho por laboratorio y tres por clínica); un caso se descartó como dengue, y los otros seis casos se confirmaron por laboratorio, pero no presentaron lesiones atípicas en la piel.

En todos los pacientes analizados, los síntomas se iniciaron entre las semanas epidemiológicas 47 a 50. De los 11 casos confirmados, cinco procedían de Cúcuta, tres, de Los Patios, y tres, de Villa del Rosario. Los pacientes residían en cuatro barrios de Cúcuta, en dos de Los Patios y en dos de Villa del Rosario, y habían sido atendidos en 14 instituciones de salud de primer, segundo y tercer nivel.

La mediana de la edad fue de 56 días (promedio $=60,9$; rango: 5 a 133). Seis de los 11 casos confirmados correspondían a niños (razón de sexo: 1,2/1). Los síntomas más frecuentes fueron: fiebre en todos, erupción cutánea en 10 e irritabilidad en 8. En algunos casos se presentó diarrea, malestar general e inapetencia. Los datos clínicos y de laboratorio se resumen en el cuadro 1.

De los 11 casos confirmados, cuatro eran menores de 15 días, cinco tenían entre uno y tres meses de edad, y dos, entre cuatro y cinco meses. Nueve de las madres asistieron a control prenatal; en ocho el parto fue por cesárea, y el peso y la talla de sus hijos estuvieron en rangos normales.

Las lesiones atípicas debidas al chikungunya se caracterizaron por ser de inicio súbito después de la fiebre, y aparecieron como una zona violácea con ampollas para luego evolucionar a lesiones ulcerosas con bordes definidos, edema, eritema con necrosis progresiva y, ocasionalmente, con secreciones (figuras 3 y 4). Las úlceras se presentaron en cuero cabelludo, boca, genitales, glúteos, pliegue poplíteo, zona perianal y abdomen, aunque $50 \%$ de ellas se presentó en glúteos y genitales, y $22 \%$ en la zona perianal (figura 5). 


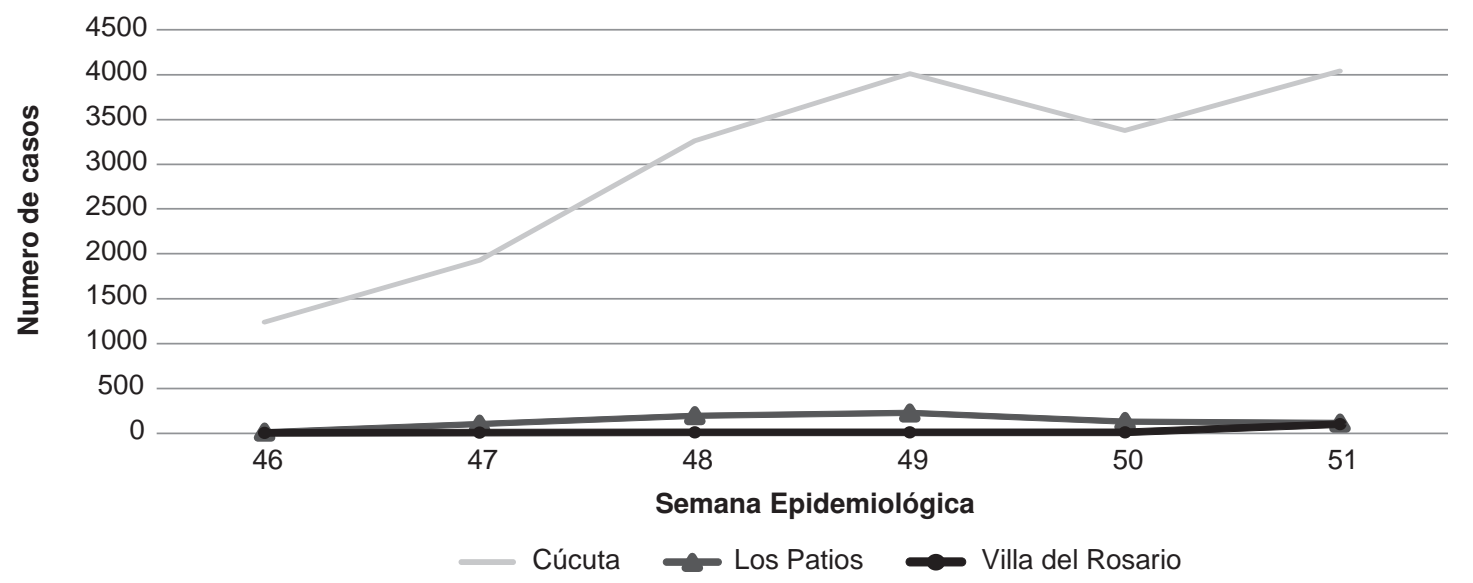

Figura 2. Número de casos de fiebre por el virus del chikungunya por semana epidemiológica (de la 46 a la 51) en Cúcuta, Villa del Rosario y Los Patios, Norte de Santander, Colombia, 2014

Fuente: Sivigila, Instituto Nacional de Salud, Colombia

\section{Resultados de los exámenes de laboratorio}

El promedio del recuento de leucocitos fue de $9.500 / \mathrm{mm}^{3}$ (mediana=8.215; rango: 3.660 a 14.500). El recuento de neutrófilos fue de $52 \%$ en promedio (mediana=51,8; rango: 11,2 a 90,9\%). En diez casos el promedio de plaquetas fue de 231.400/ $\mathrm{mm}^{3}$ (mediana=229.000; rango 106.000 a 386.000). En cinco casos se observó aumento de los niveles de aspartato aminotransferasa, con un promedio de 157,5 u/L. En nueve casos el promedio de la proteína C reactiva fue de 128,2 mg/l, rango: 18,35 a 237 mg/L).

Los once casos con lesiones mucocutáneas se confirmaron como fiebre por el virus del chikungunya, ocho por laboratorio (cinco con PCR-RT y tres con IgM), y el resto, por clínica. En tres casos se detectaron simultáneamente anticuerpos $\lg \mathrm{M}$ positivos para dengue y chikungunya; dada la edad de los menores, se concluyó que la infección por dengue era reciente, lo que sugería la infección simultánea. En uno de los casos se descartó por laboratorio el virus del chikungunya, pero tuvo resultado positivo para dengue, y la lesión apareció después de la aplicación de un medicamento en el glúteo derecho.

En cinco de los casos se detectaron Pseudomonas aeruginosa, Enterococcus faecalis y Morganella morganii en muestras de sangre, de orina y de las lesiones ulcerosas (cuadro 2). Dos de estos casos presentaron infección concomitante con dengue.

Se tomaron biopsias de las lesiones en cuatro casos (cuadro 3). Los resultados de histopatología evidenciaron necrosis de la epidermis y de la dermis superficial, con vasculitis aguda, ampollas y ulceración. No se encontraron colonias bacterianas (figura 6).

\section{Tratamiento}

Todos los pacientes estuvieron hospitalizados, dos de ellos en la unidad de cuidados intensivos. El tratamiento de las lesiones incluyó antibióticos de amplio espectro, antisépticos, regeneradores tisulares, limpieza de las heridas y, en algunos casos, desbridamiento por necrosis.

\section{Evolución}

Los diagnósticos de ingreso de los pacientes fueron: impétigo, impétigo ampolloso, dermatitis peribucal, ectima gangrenoso, fascitis necrosante, escara, piodermitis, forúnculo, absceso cutáneo, celulitis e, incluso, sífilis neonatal y meningococcemia. Un lactante de 15 días presentó lesiones costrosas en el cuero cabelludo detectadas al tercer día de la enfermedad y falleció al quinto día de hospitalización con diagnóstico de choque séptico, insuficiencia renal aguda y sepsis bacteriana del recién nacido. En el hemocultivo se detectó $P$. aeruginosa y la infección por el virus del chikungunya se confirmó mediante PCR-RT en suero. Los otros diez pacientes evolucionaron hacia la mejoría de las lesiones.

\section{Discusión}

Los brotes por fiebre del virus del chikungunya se han presentado desde hace más de cuatro décadas en la India y en regiones de África y Asia. En el 2013, se inició la epidemia en América, la cual ha afectado a varios países en los cuales hay presencia del vector, aunque ha habido casos 
Cuadro 1. Datos clínicos, demográficos y de laboratorio de los 12 casos estudiados en neonatos y lactantes, Norte de Santander, Colombia, diciembre de 2014

\begin{tabular}{|c|c|c|c|c|c|c|c|c|}
\hline Caso & Sexo & $\begin{array}{l}\text { Edad } 1 \\
\text { (días) }\end{array}$ & Signos clínicos ${ }^{2}$ & $\begin{array}{l}\text { PCR-RT } \\
\text { CHIK }\end{array}$ & $\begin{array}{l}\text { IgM } \\
\text { CHIK }\end{array}$ & $\begin{array}{c}\lg M \\
\text { Dengue }\end{array}$ & Clasificación & $\begin{array}{l}\text { Evolución } \\
\text { final }\end{array}$ \\
\hline 1 & M & 15 & $\begin{array}{l}\text { Fiebre, erupción generalizada, } \\
\text { diarrea, adinamia, irritabilidad }\end{array}$ & POS & ND & ND & $\begin{array}{l}\text { Confirmado por } \\
\text { laboratorio }\end{array}$ & Fallecido \\
\hline 2 & $\mathrm{~F}$ & 5 & $\begin{array}{l}\text { Fiebre, erupción generalizada, llanto, } \\
\text { irritabilidad }\end{array}$ & POS & NEG & ND & $\begin{array}{l}\text { Confirmado por } \\
\text { laboratorio }\end{array}$ & Vivo \\
\hline 3 & $\mathrm{~F}$ & 150 & Vómito, edema, rubor y calor local & NP & NEG & POS & Descartado & Vivo \\
\hline 4 & M & 56 & $\begin{array}{l}\text { Fiebre, irritabilidad, exantema, } \\
\text { equimosis en el cuerpo, } \\
\text { diarrea verdosa }\end{array}$ & NP & POS & POS & $\begin{array}{l}\text { Confirmado por } \\
\text { laboratorio }\end{array}$ & Vivo \\
\hline 5 & M & 90 & $\begin{array}{l}\text { Fiebre, erupción, malestar general, } \\
\text { irritabilidad, inapetencia }\end{array}$ & NP & NEG & IND & $\begin{array}{l}\text { Confirmado por } \\
\text { clínica }\end{array}$ & Vivo \\
\hline 6 & $\mathrm{~F}$ & 90 & Fiebre, erupción, irritabilidad, vómito & NP & NEG & NEG & $\begin{array}{l}\text { Confirmado por } \\
\text { clínica }\end{array}$ & Vivo \\
\hline 7 & M & 49 & $\begin{array}{l}\text { Fiebre, brote, ampollas en el cuerpo, } \\
\text { náuseas y diarrea con moco }\end{array}$ & NEG & POS & POS & $\begin{array}{l}\text { Confirmado por } \\
\text { laboratorio }\end{array}$ & Vivo \\
\hline 8 & $F$ & 90 & $\begin{array}{l}\text { Fiebre, erupción cutánea } \\
\text { generalizada, irritabilidad, } \\
\text { diarrea líquida }\end{array}$ & POS & ND & NEG & $\begin{array}{l}\text { Confirmado por } \\
\text { laboratorio }\end{array}$ & Vivo \\
\hline 9 & $F$ & 8 & $\begin{array}{l}\text { Fiebre, erupción, malestar } \\
\text { general, irritabilidad }\end{array}$ & POS & NEG & ND & $\begin{array}{l}\text { Confirmado por } \\
\text { laboratorio }\end{array}$ & Vivo \\
\hline 10 & $M$ & 14 & $\begin{array}{l}\text { Fiebre, erupción generalizada, } \\
\text { vómito, diarrea, descamación } \\
\text { generalizada de piel con vesículas }\end{array}$ & NEG & ND & ND & $\begin{array}{l}\text { Confirmado por } \\
\text { clínica }\end{array}$ & Vivo \\
\hline 11 & $\mathrm{~F}$ & 133 & $\begin{array}{l}\text { Fiebre, erupción, irritabilidad, } \\
\text { diarrea líquida }\end{array}$ & NP & POS & POS & $\begin{array}{l}\text { Confirmado por } \\
\text { laboratorio }\end{array}$ & Vivo \\
\hline 12 & $M$ & 120 & $\begin{array}{l}\text { Fiebre, irritabilidad, inapetencia, } \\
\text { exantema generalizado, petequias } \\
\text { y costras en todo el cuerpo }\end{array}$ & POS & ND & NEG & $\begin{array}{l}\text { Confirmado por } \\
\text { laboratorio }\end{array}$ & Vivo \\
\hline
\end{tabular}

F: femenino; M: masculino

${ }^{1}$ Edad al inicio de los síntomas

2 En el momento de la consulta

ND: no disponible; NP: no procesado; NEG: negativo; IND: indeterminado; POS: positivo

Fuente: base de datos del estudio y Grupo de Arbovirus del Laboratorio de Virología del Instituto Nacional de Salud

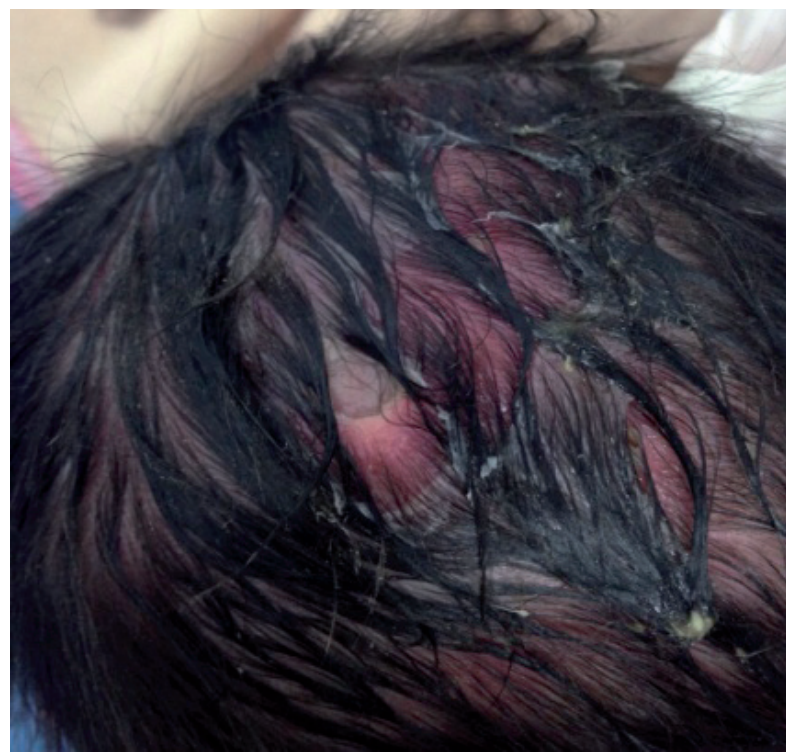

Figura 3. Lesión ulcerosa en cuero cabelludo con bordes bien definidos en el paciente 2.

Fotografía: Camilo Tovar, Urgencias, Clínica Santa Ana

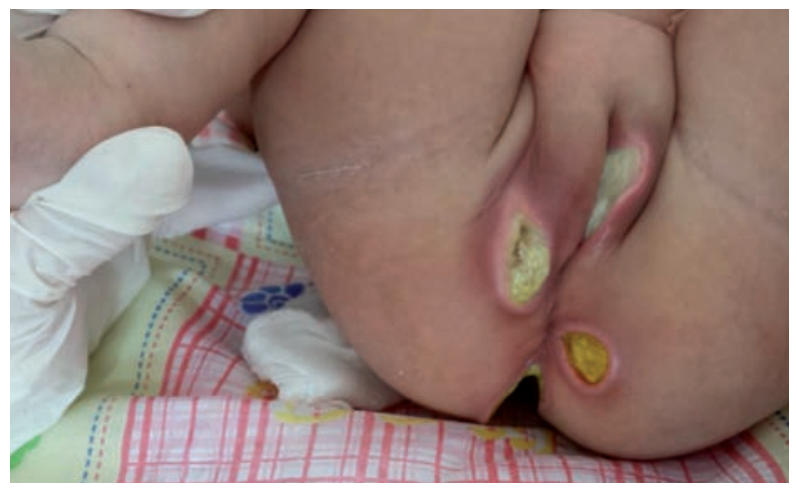

Figura 4. Lesiones múltiples que evolucionaron a úlceras en la zona genital y perianal en la paciente 11 .

Fotografía: Claudia Pérez, Cirugía Plástica, Hospital Universitario Erasmo Meoz

importados propiciados por los viajes de negocios y de turismo en el continente. En Colombia, el primer brote se presentó en septiembre de 2014, en el municipio de Mahates, Bolívar, donde se reportaron 1.134 casos hasta la semana 53 de 2014 (21). 
En el brote de la isla Reunión se presentaron 44 casos en neonatos, en $73 \%$ de los cuales se presentaron manifestaciones cutáneas caracterizadas por erupción macular (52 \%), y descamación, hiperpigmentación y dermatitis ampollosa (9\%) (22). Asimismo, se han documentado casos en menores de un año con eritema y ampollas en extremidades inferiores, glúteos y tronco (13). En la República Dominicana, se han documentado casos de transmisión neonatal, en $21 \%$ de los cuales se presentaron manifestaciones atípicas; con respecto a las manifestaciones cutáneas, $45 \%$ de los recién nacidos tuvo erupción, epidermólisis, descamación

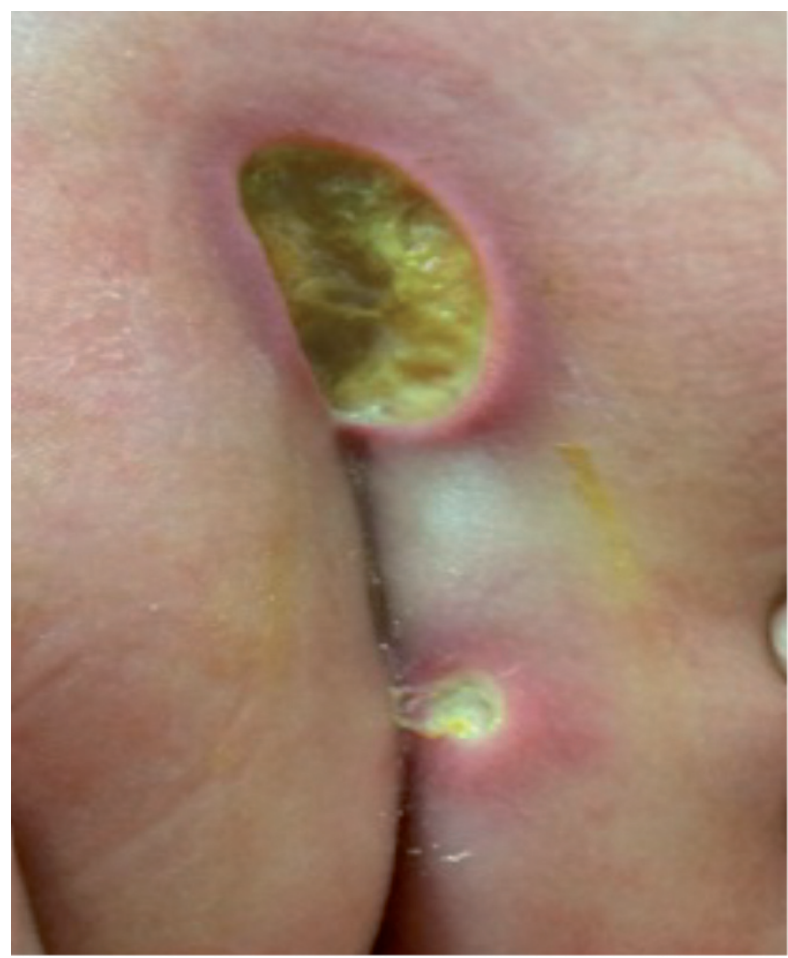

Figura 5. Lesiones múltiples que evolucionaron a úlceras en la zona perianal en el paciente 5.

Fotografía: Claudia Pérez, Cirugía Plástica, Hospital Universitario Erasmo Meoz y dermatitis ampollosa (Gómez V. Chikungunya en recién nacidos y niños: manifestaciones clínicas. Fases de la enfermedad: aguda, subaguda y crónica. Formas atípicas, severas y defunciones. Jornada de Capacitación sobre Chikunguña, Argentina, 2015).

En recién nacidos con chikungunya en India, se observaron manifestaciones cutáneas caracterizadas por cambios en la pigmentación, seguidos por la aparición de lesiones ampollosas simétricas de inicio súbito en el perineo, el pecho, el abdomen y las extremidades superiores $(23,24)$, y lesiones máculo-papulares (25). Es posible que este tipo de lesiones se presente en los recién nacidos y lactantes por la replicación viral en la epidermis, lo cual produce necrosis y alteración nuclear, así como una reacción inmunitaria que provoca infiltración de leucocitos (26). En 2006, en ese país, se reportó que $2,6 \%$ de los pacientes examinados presentaba úlceras cutáneas necróticas no intertriginosas (11). Antes de este estudio, se encontró allí que 21,3\% de los pacientes con chikungunya presentaba aftas intertriginosas y úlceras, y en los lactantes se observaron erupciones ampollosas (2,7 \%) (27).

Con respecto a las úlceras en la zona genital, se ha encontrado que en pacientes adultos con chikungunya constituyen la segunda manifestación más común (26,4\%), específicamente, en el escroto y en la base del tallo del pene en los hombres, y en los labios mayores en las mujeres (27). En otro estudio, las úlceras genitales se presentaron en una cuarta parte de los pacientes examinados (26) semanas después del inicio de la fiebre; las úlceras se caracterizaban por ser redondas u ovaladas, con bordes socavados, tejido de granulación sano en el fondo, y eritema y engrosamiento en la piel circundante (28).

En el presente estudio, se presentaron 12 casos de lesiones que evolucionaron a úlceras, de los cuales se confirmaron 11 como fiebre de chikunguña

Cuadro 2. Resultados de los cultivos de las lesiones de neonatos y lactantes con lesiones mucocutáneas, Norte de Santander, diciembre de 2014

\begin{tabular}{clll}
\hline Caso & Muestra & Resultado & Clasificación del caso \\
\hline 1 & Sangre & Pseudomonas aeruginosa & Confirmado por laboratorio \\
4 & Miembro inferior derecho y región sacra & Pseudomonas aeruginosa & Confirmado por laboratorio \\
5 & Región inguinal & Pseudomonas aeruginosa & Confirmado por clínica \\
& Orina & Enterococcus faecalis & \\
6 & Vulva & Pseudomonas aeruginosa & Confirmado por clínica \\
11 & Vagina & Pseudomonas aeruginosa & Confirmado por laboratorio \\
& Región interglútea & Morganella morganii & \\
\hline
\end{tabular}

Fuente: historias clínicas, Hospital Universitario Erasmo Meoz 
Cuadro 3. Resultados de las biopsias de las lesiones mucocutáneas en neonatos y lactantes, Norte de Santander, diciembre de 2014

\begin{tabular}{|c|c|c|}
\hline Caso & Muestra & Diagnóstico patológico \\
\hline 4 & $\begin{array}{l}\text { Piel del miembro } \\
\text { inferior derecho }\end{array}$ & $\begin{array}{l}\text { 1) Necrosis dermoepidérmica } \\
\text { 2) Ulceración } \\
\text { 3) Vasculitis }\end{array}$ \\
\hline 7 & Piel del abdomen & $\begin{array}{l}\text { 1) Necrosis epidérmica } \\
\text { 2) Úlcera central } \\
\text { 3) Vasculitis aguda }\end{array}$ \\
\hline 8 & $\begin{array}{l}\text { Piel de la vulva } \\
\text { y del glúteo }\end{array}$ & $\begin{array}{l}\text { 1) Necrosis dermoepidérmica } \\
\text { 2) Vasculitis aguda }\end{array}$ \\
\hline 12 & $\begin{array}{l}\text { Piel de la región } \\
\text { interglútea }\end{array}$ & $\begin{array}{l}\text { 1) Vasculitis aguda } \\
\text { 2) Ampollas en la piel } \\
\text { 3) Correlacionar con hallazgos } \\
\text { clínicos }\end{array}$ \\
\hline
\end{tabular}

Fuente: Laboratorio de Patología, Hospital Universitario Erasmo Meoz

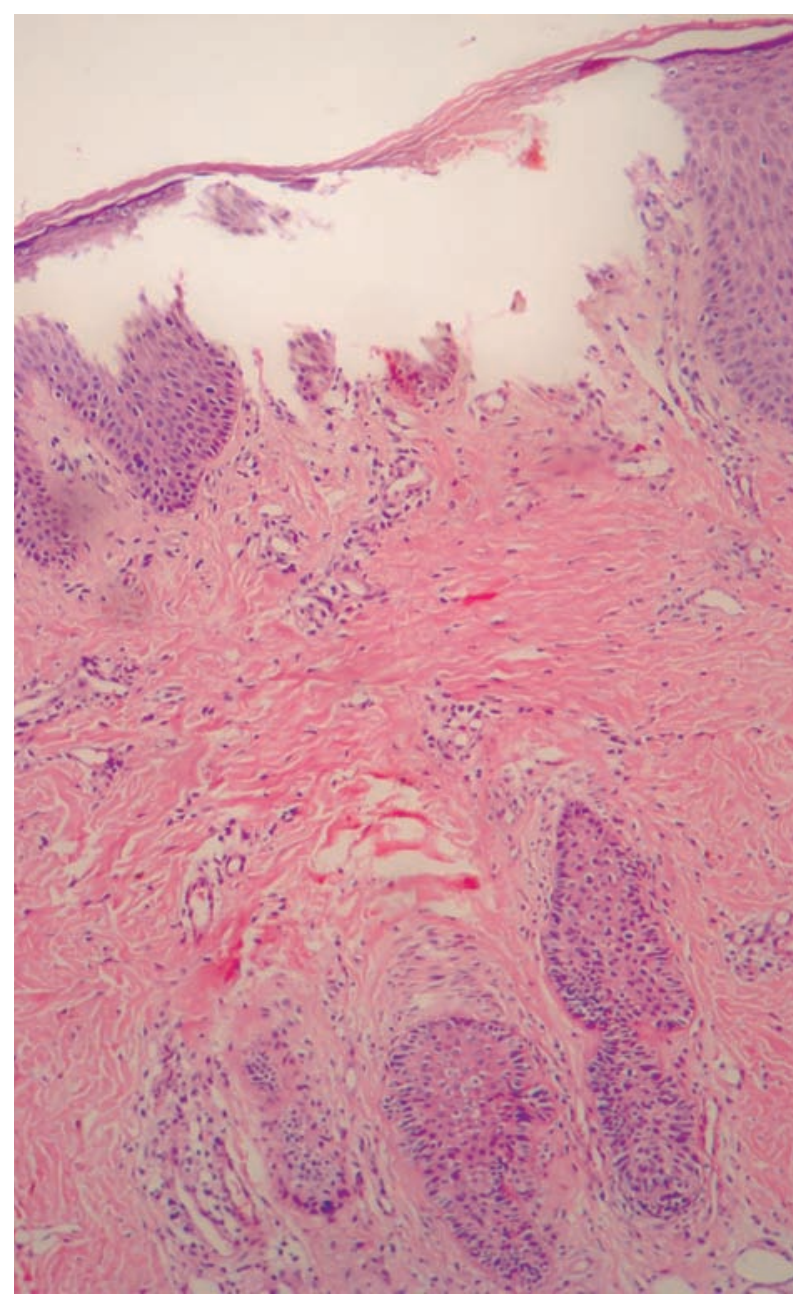

Figura 6. Biopsia de piel de una lesión ulcerada en la región interglútea. Se observó necrosis de la epidermis y dermis superficial con vasculitis aguda. Hematoxilina y eosina, 25X. Fuente: Laboratorio de Patología, Hospital Universitario Erasmo Meoz con manifestaciones mucocutáneas atípicas, y en nueve se encontraron úlceras redondeadas $u$ ovaladas en la zona perianal o genital y en los pliegues de las extremidades inferiores.

En todos los casos, las lesiones ulcerosas eran múltiples y aparecieron después de los episodios de fiebre, como se ha reportado en otros estudios, en los cuales se informó que comenzaron al cabo de tres o cuatro días de la aparición de la fiebre (29). Los pacientes no estaban inmunosuprimidos, sin embargo, se encontraron inmunoglobulinas por debajo de los valores normales en dos de los pacientes. En tres de ellos se encontraron anticuerpos IgM para la fiebre del chikungunya y en tres se confirmó la infección mediante PCR-RT. Se enviaron muestras de las lesiones para cultivo y en cinco pacientes se aisló $P$. aeruginosa, sin embargo, se descartó una infección asociada a la atención en salud, ya que no se cumplían los criterios de la definición de caso establecida para este evento.

Las manifestaciones mucocutáneas observadas en los pacientes de este estudio son las primeras que se reportan en Colombia debidas a la fiebre de chikungunya. Las úlceras evolucionaron rápidamente, probablemente por cambios genéticos en el virus y la reacción inmunitaria frente a su presencia. Dichas lesiones constituyen formas graves de la fiebre de chikungunya que afectan principalmente a recién nacidos y lactantes, y deben ser consideradas por el personal médico para el diagnóstico diferencial en niños pequeños.

Las úlceras se atribuyen a vasculitis desencadenadas por el virus (27) y se caracterizan por una o más lesiones. En los pacientes del presente estudio, evolucionaron de forma rápida a partir de una zona violácea con ampollas hasta convertirse en lesiones con bordes definidos, edema, eritema con necrosis progresiva y secreciones de color amarillo. Los pacientes recibieron un tratamiento conservador basado en los síntomas, con lo cual evolucionaron satisfactoriamente.

Mediante $\lg \mathrm{M}$ se confirmaron tres casos de chikungunya $y$, también, se registraron resultados positivos para dengue, lo que podría indicar la presencia de infección concomitante. Las muestras de suero de estos tres pacientes se recolectaron entre los días 5 y 14 después del inicio de los síntomas. Aunque se sabe que cerca de $93 \%$ de los pacientes con dengue desarrollan anticuerpos IgM detectables entre los 6 y los 10 días del inicio de la enfermedad, y que en $99 \%$ de los pacientes 
se detectan anticuerpos IgM entre los días 10 y 20 de la infección (30), la posibilidad de una reacción cruzada con el virus del chikungunya no se evaluó porque no se hicieron estudios adicionales para confirmar la infección por el virus del dengue mediante PCR-RT, cultivo del virus o seroconversión de IgG en sueros pareados. En un caso se reportó un resultado positivo para dengue y se descartó chikungunya mediante IgM. En cuatro de los casos se mantuvo la hipótesis de la transmisión vertical de madre a hijo.

Debido a que $A$. aegypti está presente en la región, es necesario mantener las acciones de prevención y control locales para disminuir la circulación del vector, y adelantar actividades de comunicación del riesgo entre la población, ya que se encontraron suposiciones de tipo cultural sobre la enfermedad.

Asimismo, habría que priorizar la atención de las mujeres gestantes por ser una población en riesgo. Se sugiere que, en el momento del nacimiento de los hijos de madres con sospecha de chikungunya, se les haga seguimiento para descartar complicaciones. Se recomienda, igualmente, hacer los estudios pertinentes en estos lactantes para evaluar las secuelas, y estudios retrospectivos, para explorar otras variables clínicas y epidemiológicas que aporten al conocimiento de esta enfermedad en el país.

Los resultados del presente estudio permitieron confirmar que la fiebre del chikungunya causó manifestaciones atípicas mucocutáneas en recién nacidos y lactantes, probablemente relacionadas con su reacción inmunitaria frente al virus. Estos casos deben tener prioridad para el tratamiento y para evitar complicaciones.

\section{Agradecimientos}

Al Grupo de Vigilancia en Salud Pública del Instituto Departamental de Salud de Norte de Santander, a las secretarías de salud de los municipios de Cúcuta, Los Patios y Villa del Rosario, al Hospital Universitario Erasmo Meoz, especialmente a Héctor Francisco Flórez Santaella, a la Clínica Santa Ana, y al Grupo de Arbovirus del Laboratorio de Virología del Instituto Nacional de Salud por el procesamiento de las muestras.

\section{Conflicto de intereses}

Los autores declaran no tener conflicto de intereses con respecto al estudio.

\section{Financiación}

Este estudio fue financiado por la Dirección de Vigilancia y Análisis del Riesgo en Salud Pública del Instituto Nacional de Salud, el Instituto Departamental de Salud de Norte de Santander y la Secretaría de Salud de Cúcuta.

\section{Referencias}

1. Morrison T. Reemergence of Chikungunya virus. J Virol. 2014;88:11644-7. http://dx.doi.org/10.1128/JVI.01432-14

2. Rezza G, Nicoletti L, Angelini R, Romi R, Finarelli AC, Panning $\mathrm{M}$, et al. Infection with Chikungunya virus in Italy: An outbreak in a temperate region. Lancet. 2007;370:1840-6. http://dx.doi.org/10.1016/S0140-6736(07) 61779-6

3. Gérardin P, Barau G, Michault A, Bintner M, Randrianaivo $\mathbf{H}$, Choker G, et al. Multidisciplinary prospective study of mother-to-child Chikungunya virus infections on the Island of La Réunion. PLoS Med 2008;5:e60. http://dx.doi. org/10.1371/journal.pmed.0050060

4. Moro M, Gagliotti C, Silvi G, Angelini R, Sambri V, Rezza G, et al. Chikungunya virus in North-Eastern Italy: A seroprevalence survey. Am J Trop Med Hyg. 2010;82:50811. http://dx.doi.org/10.4269/ajtmh.2010.09-0322

5. Diallo M, Thonnon J, Traore-Lamizana M, Fontenille D. Vectors of Chikungunya virus in Senegal: Current data and transmission cycles. Am J Trop Med Hyg. 1999;60:281-6.

6. Thiberville SD, Moyen $\mathrm{N}$, Dupuis-Maguiraga $\mathrm{L}$, Nougairede A, Gould EA, Roques P, et al. Chikungunya fever: Epidemiology, clinical syndrome, pathogenesis and therapy. Antiviral Res. 2013;99:345-70. http://dx.doi. org/10.1016/j.antiviral.2013.06.009

7. Pialoux G, Gaüzère B, Jauréguiberry $S$, Strobel $\mathbf{M}$. Chikungunya, an epidemic arbovirosis. Lancet Infect Dis. 2007;7:319-27. http://dx.doi.org/10.1016/S1473-3099(07) 70107-X

8. Organización Panamericana de Salud. Preparación y respuesta ante la eventual introducción del virus Chikungunya en las Américas. Washington, D.C.: OMS; 2011. Fecha de consulta: 20 de enero de 2015. Disponible en: http://www1. paho.org/hq/dmdocuments/CHIKV_Spanish.pdf.

9. Pimentel R, Skewes-Ramm, Moya J. Chikungunya en la República Dominicana: lecciones aprendidas en los primeros seis meses. Rev Panam Salud Pública. 2014;36:336-41.

10. Pialoux G, Gaüzère $\mathbf{B}$, Strobel $\mathbf{M}$. Infection à virus Chikungunya: revue générale par temps d'épidémie. Med Mal Infect. 2006;36:253-63. http://dx.doi.org/10.1016/j. medmal.2006.04.002

11. Ramesh M, Yashaswi R, Amith R, Nandakishore B, Sukumar D, Martis J, et al. Mucocutaneous manifestations of Chikungunya fever: A study from an epidemic in coastal Karnataka. Indian J Dermatol. 2011;56:290-4. http://dx.doi. org/10.4103/0019-5154.82483

12. Economopoulou A, Domínguez M, Helynck B, Sissoko D, Wichmann O, Quenel P, et al. Atypical Chikungunya virus infections: Clinical manifestations, mortality and risk 
factors for severe disease during the 2005-2006 outbreak on Reunion. Epidemiol Infect. 2009;137:534-41. http://dx. doi.org/10.1017/S0950268808001167

13. Robin S, Ramful D, Zettor J, Benhamou L, Jaffar M, Rivière $\mathbf{J}$, et al. Severe bullous skin lesions associated with Chikungunya virus infection in small infants. Eur $\mathrm{J}$ Pediatr. 2010;169:67-72. http://dx.doi.org/10.1007/s00431-009-0986-0

14. Organización Mundial de la Salud. Chikungunya. Fecha de consulta: 20 de enero de 2015. Disponible en: http:// www.who.int/mediacentre/factsheets/fs327/es/.

15. Organización Panamericana de la Salud. Número de casos reportados de Chikungunya en países o territorios de las Américas 2013-2014. Semana epidemiológica 51 de 2014. Fecha de consulta: 20 de enero de 2015. Disponible en: http://www.paho.org/hq/index.php?option=com_topics\& view $=$ readall $\&$ cid $=5932 \&$ ltemid $=40931$ lang $=e s$.

16. Instituto Nacional de Salud. Boletín Epidemiológico Nacional, Semana Epidemiológica 51 de 2014. Bogotá: Instituto Nacional de Salud; 2014. Fecha de consulta: 20 de enero de 2015. Disponible en: http://www.ins.gov.co/ boletin-epidemiologico/Boletn\%20Epidemiolgico/2014\%20 Boletin\%20epidemiologico\%20semana\%2051.pdf.

17. Martínez M, Gómez S. Chikungunya en Colombia, el inicio de la transmisión autóctona, 2014. Inf Quinc Epidemiol Nac. 2014;19:260-79. Fecha de consulta: 21 de enero de 2015. Disponible en: http://www.ins.gov.co/iqen/IQUEN/IQEN\%20 vol\%2019\%202014\%20num\%2018.pdf.

18. Instituto Nacional de Salud. Lineamientos de vigilancia en salud pública, entomológica y de laboratorio en transmisión autóctona del virus chikungunya en Colombia. Fase II. Bogotá: Instituto Nacional de Salud; 2014. Fecha de consulta: 21 de enero de 2015. Disponible en: http://www. ins.gov.co/Noticias/Chikungunya/Lineamientos\%20de\%20 vigilancia\%20chikungunya\%202014.pdf.

19. Alcaldía Municipal de Los Patios. Plan de Desarrollo Municipio de Los Patios, 2012-2015. Los Patios: Alcaldía; 2012. Fecha de consulta: 21 de enero de 2015. Disponible en: http://cdim.esap.edu.co/BancoMedios/Documentos\%20 PDF/lospatiosnortedesantanderpd20122015.pdf.

20. Alcaldía Municipal de Villa del Rosario. Plan de Desarrollo - Municipio de Villa de Rosario, 2012-2015. Villa del Rosario: Alcaldía; 2012. Fecha de consulta: 21 de enero de 2015. Disponible en: http://www.villadelrosario-nortedesantander. gov.co/apc-aa-files/6435643038323665303966363562356 1/version-final-plan-desarr-documento-tecnico.pdf-
21. Instituto Nacional de Salud. Grupo de Enfermedades Transmitidas por Vectores. Resumen, Chikunguña a semana 53. Bogotá: Instituto Nacional de Salud; 2014. Fecha de consulta: 21 de enero de 2015. Disponible en: http://www.ins.gov.co/Noticias/Chikungunya/Forms/ Alltems.aspx?Paged=TRUE\&p_SortBehavior $=0 \& p$ orden $=\& p \_I D=89 \&$ PageFirstRow $=61 \& \&$ View $=\{F 354 C 7 \overline{7}$ A-609B-4AE6-8D9D-7C203FE1526F\}

22. Institut de Veille Sanitaire. Surveillance des formes émergentes hospitalières de chikungunya, la Réunion, avril 2005 - mars 2006. Rapport détaillé. Saint Maurice, France: INVS; 2007. Fecha de consulta: 30 de agosto de 2015. Disponible en: http://www.invs.sante.fr/publications/2007/ chik_surveillance_2007/chik_surveillance_2007.pdf.

23. Valamparampil J, Chirakkarot S, Letha S, Jayakumar C, Gopinathan K. Clinical profile of Chikungunya in infants. Indian J Pediatr. 2009;76:151-5. http://dx.doi.org/10.1007/ s12098-009-0045-x

24. Riyaz N, Riyaz A, Rahima A, Latheef E, Anitha P, Aravindan $\mathrm{K}$, et al. Cutaneous manifestations of chikungunya during a recent epidemic in Calicut, north Kerala, south India. Indian J Dermatol Venereol Leprol. 2010;76:671-6. http://dx.doi. org/10.4103/0378-6323.72466

25. Seetharam KA, Sridevi K, Vidyasagar P. Cutaneous manifestations of Chikungunya fever. Indian Pediatr. 2012; 49:51-3.

26. Inamadar A, Palit A, Sampagavi W, Raghunath S, Deshmukh N. Cutaneous manifestations of Chikungunya fever: Observations made during a recent outbreak in South India. Int J Dermatol. 2008;47:154-9. http://dx.doi. org/10.1111/j.1365-4632.2008.03478.x

27. Prashant S, Kumar A, Basheeruddin D, Chowdhary T, Madhu B. Cutaneous manifestations in patients suspected of Chikungunya disease. Indian J Dermatol. 2009;54:12831. http://dx.doi.org/10.4103/0019-5154.53186

28. Mishra K, Rajawat V. Chikungunya-induced genital ulcers. Indian J Dermatol Venereol Leprol. 2008;74:383-4. http:// dx.doi.org/10.4103/0378-6323.42903

29. Rajapakse S, Rodrigo C, Rajapakse A. Atypical manifestations of Chikungunya infection. Trans $\mathrm{R}$ Soc Trop Med Hyg. 2010;104:89-96. http://dx.doi.org/10.1016/j. trstmh.2009.07.031

30. Faingezicht I, Ávila M. Diagnóstico clínico y de laboratorio del paciente con el dengue. Rev Med Hosp Nac Niños (Costa Rica). 1999;34:33-41. 